\section{An Evaluation of the Light Output from 22 Contemporary Light Curing Units}

Carlos José Soares ${ }^{1}$, Monise de Paula Rodrigues ${ }^{1}$, Laís Rani Sales Oliveira ${ }^{1}$, Stella Sueli Lourenço Braga', Luciana Mendes Barcelos ${ }^{1}$, Gisele Rodrigues da Silva', Marcelo Giannini², Richard Bengt Price ${ }^{3}$

\author{
'Department of Operative Dentistry, \\ UFU - Universidade Federal de \\ Uberlândia, Uberlândia, MG, Brazil \\ ${ }^{2}$ Department of Restorative \\ Dentistry, Piracicaba Dental School, \\ UNICAMP - Universidade Estadual \\ de Campinas, Piracicaba, SP, Brazil \\ ${ }^{3}$ Department of Dental Clinical \\ Sciences, Dalhousie University, \\ Halifax, Nova Scotia, Canada
}

Correspondence: Dr. Carlos José Soares, Avenida Pará, 1720, Bloco 4L, Anexo A, Sala 42, Campus Umuarama, 38400-902 Uberlândia, MG, Brasil. Tel +55-34-3225-8106. e mail: carlosjsoares@ufu.br

Key Words: light curing unit, radiant power, irradiance, emission spectrum, MARC patient simulator

\section{Introduction}

Use of light cured dental resins is now ubiquitous $(1,2)$ and the light-curing unit (LCU) should be considered as an essential piece of equipment in every dental office. A significant volume of dental research and clinical procedures involve the use of composite resin and a dental curing light (3). To achieve the manufacturer's intended mechanical properties for light cured resin-based composites (RBCs), the material must receive from the LCU sufficient energy at the appropriate wavelengths $(2,4-8)$.

Several different types of LCUs are available: quartztungsten-halogen $(\mathrm{OTH})$, plasma arc (PAC), laser and different types of light emitting diode (LED) units (9). These LCUs range in price and unfortunately the cost of the unit is one of the first factors that some clinicians consider when purchasing a new curing light. However, when choosing a new LCU it is important to understand what it does and what its specifications mean. The use of a single "irradiance" value that manufacturers often quote to describe the output from the LCU should be interpreted with caution, as it implies that this single irradiance value describes the light that every part of the resin composite is receiving (2). However, this irradiance (incident irradiance) value, expressed in milliWatt per square centimeter $\left(\mathrm{mW} / \mathrm{cm}^{2}\right)$, is derived from the total radiant power (Watts) delivered by the LCU onto a surface of known dimensions $\left(\mathrm{cm}^{2}\right)$. It can only reflect an average value over the total surface area (2) and it does not take into account any non-uniformity in the light output across the tip of the LCU, or the distance from the tip.

The clinicians also need to know the emission spectrum of the light emitted from the LCU, so that they can match the light to the RBC they are using $(4,5,10)$. The output from conventional single peak LED units is designed to activate the camphorquinone photoinitiator $(1,5,11)$. Camphorquinone (CO) is the traditional initiator used in most RBCs and it is mostly activated by blue light peaking at $468 \mathrm{~nm}$ wavelength. Several new photoinitiators have been developed as an alternative to $\mathrm{CO}$, e.g., trimethylbenzoyldiphenylphosphine oxide (TPO, ranging from 375 to 410 $\mathrm{nm}$ ) and 1-phenyl-1,2-propanedione (PPD, maximum wavelength $\approx 410 \mathrm{~nm})(12,13)$. Some broad-spectrum LED units include additional LED emitters that produce light at these lower wavelengths, which are in the 'violet' range, to make these LCUs compatible with a wider range of 
photoinitiators $(1,8,14)$. However, unless carefully designed, the addition of a variety of different wavelength LEDs within the light source can affect negatively the uniformity of the light beam from the LCU. This may then affect both the irradiance and wavelengths received at different locations

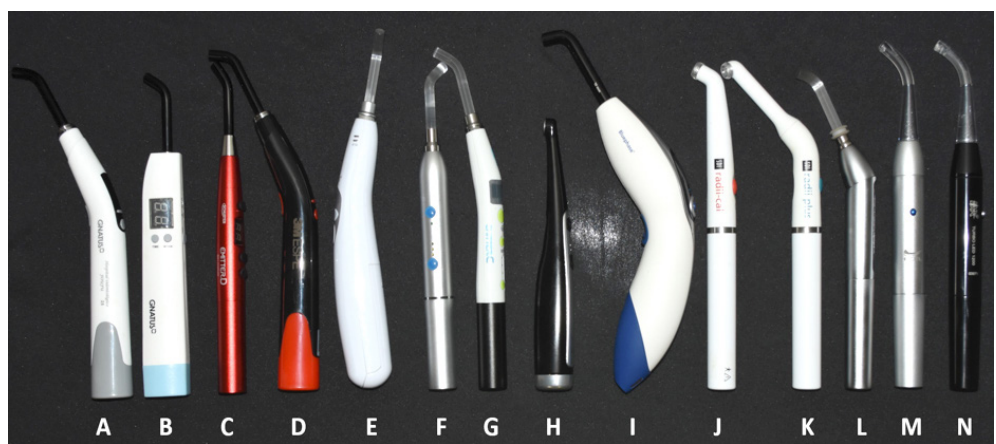

Figure 1. A: Optilight; B: Optilight Color; C. Emitter D; D. High-Power 3M-ESPE; E. Led Lux II; F. DB 685; G. Emitter C; H. VALO Cordless; I. Bluephase G2; J. Radii-cal); K. Radii plus; L. Poly Wireless; M. EC500; N. DX Turbo Led 1200.

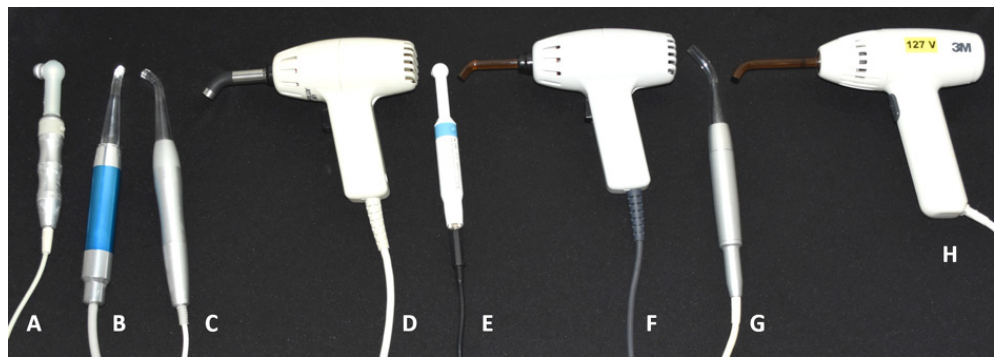

Figure 2. A: Kon-lux; B: Alt Lux II; C. BioLux Standard; D. Optilux 501; E. TL-01; F. Demetron LC; G. EC450; H. XL 3000.

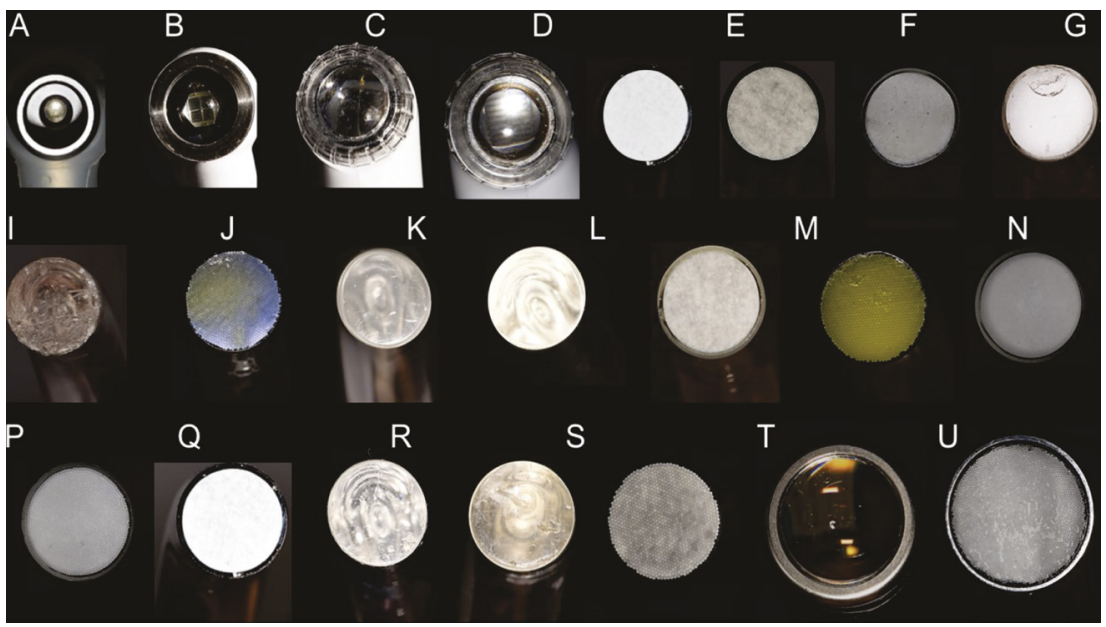

Figure 3. Images of the light tips from smallest to largest diameter: A: KON-LUX; B. TL-01; C. Radii plus; D. Radii cal; E. Optilight Color; F. High Power 3M/ESPE; G. DB 685; H. Led Lux II; I. DX Turbo LED; J. Demetron LC; K. EC500; L. EC450; M. Emiter D; N. XL 3000; 0. Emiter C; P. Poly Wireless; Q. Optilight Max; R. Alt Lux II; S. BioLux Standard; T. Bluephase G2; U. Valo Cordeless; V. Demetron 501. across the restoration and thus alter the polymerization of the RBC.

The sales of budget LCUs has increased substantially. Although it might seem attractive to purchase a budget $L C U$, the performance of this equipment may reduce the clinical longevity of restorations. Several previous studies that have evaluated dental LCUs have used dental radiometers, but such devices are known to be inaccurate. In addition, they do not report the radiant power or the emission spectrum (15). Therefore, the aim of this study was to analyze the radiant power, irradiance and emission spectrum of a wide range of commercially available curing lights. As the ability of the LCU to access the restoration is also an important factor, the effect of the restoration's location in the mouth was also evaluated. Although previous studies have used a minimum acceptable irradiance value of irradiance value of $300 \mathrm{~mW} / \mathrm{cm}^{2}$, this was time when dentists used a curing light for 40 to $60 \mathrm{~s}$ per increment of RBC. Given today's norm of 10 to $20 \mathrm{~s}$ exposure time per increment, an irradiance value of $500 \mathrm{~mW} /$ $\mathrm{cm}^{2}$ was defined in this study as the minimum threshold for adequate photocuring and producing adequate mechanical properties to the RBC. The null hypotheses were that: a) The OTH and the LED LCUs would deliver similar spectrum and irradiance to simulated restorations in the anterior and posterior teeth; b) The OTH and the LED LCUs would deliver similar radiant powers; $c$ ) The different light curing designs would not affect the irradiance delivered to simulated restorations in the anterior and posterior teeth.

\section{Material and Methods}

Twenty-two different commercially available LCUs (Figs. 1 and 2) were tested: 17 were monowave LED, 2 were multiple peak LED units and 3 were QTH units (Table 1).

\section{Light Tip Area and Radiant Power}

The tips of the LCUs were photographed (Fig. 3). The light tip internal and external diameters were measured. The tip area was calculated from the internal radius 
of the light tip in a standardized way using Image J software (National Institutes of Health, Bethesda, MD, USA).

The radiant power from the was measured using a 3-watt laboratory grade handheld photodiode power meter (Nova, Ophir Spiricon, Logan, UT, USA) that had a 10x10 mm measurement aperture (PD300-3W, Ophir Spiricon). Most of the LCUs were new or had been used for a very short time. The QTH LCUs were provided new halogen light bulbs before the test. Where appropriate, a fully charged battery was used for all the measurements. Three measurements were made with the tip of the LCUs positioned as close as possible to the surface of the sensor without touching and the LCU was set to run for a $20 \mathrm{~s}$ exposure time. To provide an average reading, the radiant power output for each LCU was set as the power delivered at the tenth second of $20 \mathrm{~s}$ light exposure. This removed the effect of any spike in the light output when the unit was turned on in the first few seconds.

\section{Irradiance}

The design of the LCUs was very different, some were gun style, some were pen style, some used light guides and some had the LED light source located at the tip (Figs. 1 and 2). The light output from the LCUs was measured using

Table 1. Characteristics of the LCUs

\begin{tabular}{|c|c|c|c|c|c|}
\hline $\begin{array}{l}\text { Light Curing } \\
\text { Units/LCU }\end{array}$ & $\begin{array}{l}\text { LCU serial } \\
\text { number }\end{array}$ & $\begin{array}{c}\text { LCU type/ } \\
\text { wavelength emission }\end{array}$ & $\begin{array}{l}\text { Battery/ } \\
\text { Mains }\end{array}$ & Tip/light conductor & Manufacturer \\
\hline $\begin{array}{l}\text { DX Turbo } \\
\text { LED } 1200\end{array}$ & 3871 & LED/monowave & Battery & Plastic/translucent & DX, Ribeirão Preto, SP, Brazil \\
\hline EC500 & 1713 & LED/monowave & Battery & Plastic/translucent & Ecel, Ribeirão Preto, SP, Brazil \\
\hline Poly Wireless & 2015114907 & LED/monowave & Battery & Plastic/translucent & Kavo Kerr, Joinville, SC, Brazil \\
\hline DB 685 & 1072695 & LED/monowave & Battery & $\begin{array}{l}\text { Optical fiber/ } \\
\text { translucent }\end{array}$ & $\begin{array}{l}\text { Dabi Atlante, Ribeirão } \\
\text { Preto, SP, Brazil }\end{array}$ \\
\hline Emitter C & L1541282C & LED/monowave & Battery & $\begin{array}{l}\text { Optical fiber/ } \\
\text { translucent }\end{array}$ & Schuster, Santa Maria, RS, Brazil \\
\hline Emitter D & 7702023 & LED/monowave & Battery & Optical fiber/black & Schuster, Santa Maria, RS, Brazil \\
\hline Optilight Color & 7000126059 & LED/monowave & Battery & Optical fiber/black & Gnatus, Ribeirão Preto, SP, Brazil \\
\hline Optilight Max & 881778249 & LED/monowave & Battery & Optical fiber/black & Gnatus, Ribeirão Preto, SP, Brazil \\
\hline $\begin{array}{l}\text { High Power } \\
\text { 3M-ESPE }\end{array}$ & 7000204142 & LED/monowave & Battery & Optical fiber/black & 3M-ESPE, St Paul, MN, USA \\
\hline Radii plus & 52003 & LED/monowave & Battery & None & $\begin{array}{c}\text { SDI, Basywater, } \\
\text { Victoria, Australia }\end{array}$ \\
\hline Radii cal & EA1015CL & LED/monowave & Battery & None & $\begin{array}{c}\text { SDI, Basywater, } \\
\text { Victoria, Australia }\end{array}$ \\
\hline Alt Lux II & 2184 & LED/monowave & Mains & Plastic/translucent & Alt, Ribeirão Preto, SP, Brazil \\
\hline BioLux Standard & 16192 & LED/monowave & Mains & Plastic/translucent & Alt, Ribeirão Preto, SP, Brazil \\
\hline EC450 & EL003581 & LED/monowave & Mains & Plastic/translucent & Ecel, Ribeirão Preto, SP, Brazil \\
\hline Led Lux II & 34512 & LED/monowave & Mains & $\begin{array}{l}\text { Optical fiber/ } \\
\text { translucent }\end{array}$ & Ortus, Campo Mourão, PR, Brazil \\
\hline KON-LUX & KP3104676 & LED/monowave & Mains & None & $\begin{array}{l}\text { Kondentech, São } \\
\text { Carlos, SP, Brazil }\end{array}$ \\
\hline TL-01 & 8039 & LED/monowave & Mains & None & $\begin{array}{l}\text { Spring Health, } \\
\text { Norristown, PA, USA }\end{array}$ \\
\hline Bluephase G2 & 505212 & LED/multi-peak & Mains & Optical fiber/black & $\begin{array}{c}\text { Ivoclar Vivadent, Schaan, } \\
\text { Liechtenstein }\end{array}$ \\
\hline VALO Cordless & C33856 & LED/multi-peak & Battery & None & $\begin{array}{l}\text { Ultradent, South Jordan, } \\
\text { UT, United States }\end{array}$ \\
\hline $\begin{array}{l}\text { Curing Light } \\
\text { XL } 3000\end{array}$ & 207723 & QTH & Mains & Optical fiber/black & 3M-ESPE, St Paul, MN, USA \\
\hline Demetron LC & 62001338 & QTH & Mains & Optical fiber/black & Kerr, Orange, CA, USA \\
\hline Optilux 501 & 53115507 & QTH & Mains & Optical fiber/black & Kerr, Orange, CA, USA \\
\hline
\end{tabular}


a MARC patient simulator (MARC-PS, BlueLight Analytics, Halifax, NS, Canada). This device measures the irradiance $\left(\mathrm{mW} / \mathrm{cm}^{2}\right)$, spectral emission $(\mathrm{nm})$, and radiant exposure $\left(\mathrm{J} / \mathrm{cm}^{2}\right)$ delivered from light-curing devices to simulated dental restoration sites on the facial of the maxillary central incisors and in the occlusal of a maxillary second molar in a dental mannequin head $(16,17)$. The detectors were connected to a laboratory grade fiberoptic spectrometer (USB4000, Ocean Optics, Dunedin, FL, USA) inside the mannequin head. The anterior detector is located at the facial surface of the maxillary central incisors, simulating the surface of a class III restoration and the other detector is at the bottom of a $4 \mathrm{~mm}$ deep Class I preparation in the maxillary left second molar $(16,18)$.

The LCUs were tested in their standard output mode for $10 \mathrm{~s}$. The mouth opening at incisors region was fixed at $35 \mathrm{~mm}$. One skilled operator made all the light exposures, following these three guidelines:

1. the LCU was placed directly over and as perpendicular to the sensor surface as possible ; 2 . the LCU tip was stabilized as close as possible to the surface during the exposure time; 3 . the operator wore appropriate blue light blocking glasses and correctly positioned the mannequin head to provide maximum visibility and access to the restoration $(16,19)$.

The irradiance measurements were conducted independently at both anterior and posterior sensors, three times in a random order for each LCU (Fig. 4). The MARC software calculated the irradiance $\left(\mathrm{mW} / \mathrm{cm}^{2}\right)$ received by the sensors from each LCU. The averages of the three measurements recorded for each $\mathrm{LCU}$ and from each sensor were obtained.

\section{Statistical Analysis}

Data were analyzed for normal distribution and homoscedasticity using the Shapiro-Wilk test and Levene's test, respectively. Two-way ANOVA (22x2) was used to compare the light output for two study factors: the LCU
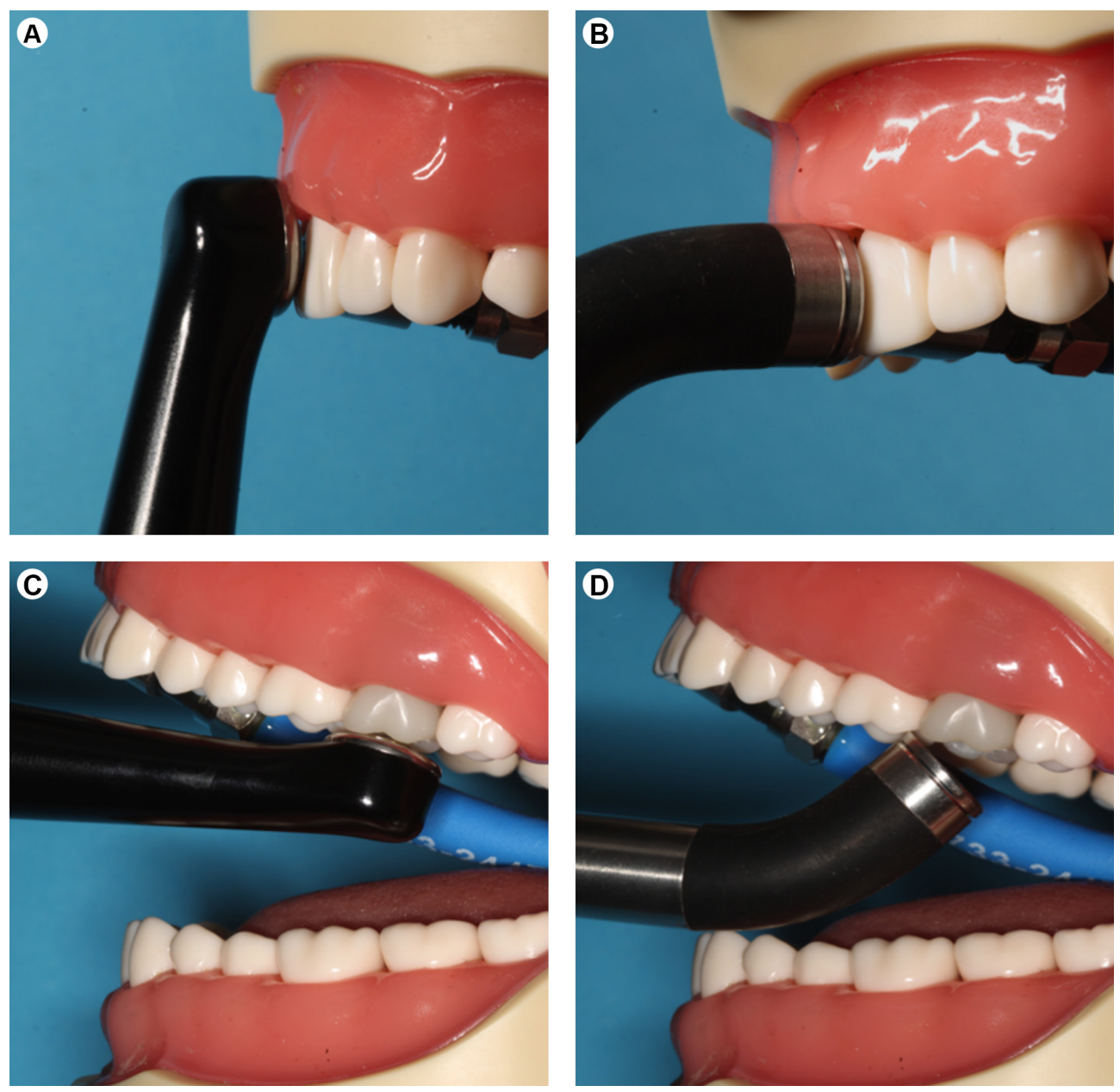

Figure 4. LCUs positioned at anterior sensor showing the ideal position of the tip parallel to the surface of the restoration, A: Valo Cordless and B: Demetron 501. LCUs positioned at posterior sensor showing that: C: Valo Cordless maintains ideal position of the tip parallel to the surface of the restoration, and D: Demetron 501 light tip could not be positioned parallel to the occlusal surface at the same inter incisal opening. 
(22 LCUs) and the tooth region (anterior and posterior location). The power data was analyzed by one-way ANOVA. All tests were performed at a significance level of $\alpha=0.05$ and all analyses were performed by the Sigma Plot version 13.1 statistical package (Systat Software Inc., San Jose, CA, USA). The emission spectra ( $\mathrm{nm}$ ) were analyzed descriptively.

\section{Results}

The LCU emitted powers ( $\mathrm{mW}$ ) are in Table 2. One-way ANOVA showed that the radiant power values differed significantly among the LCUs $(p<0.001)$. Tukey test showed that Bluephase $\mathrm{G} 2$ and Optilight Max delivered the highest radiant power, and KON-LUX, Altlux II and Biolux Standard delivered the lowest radiant power.

The internal diameter, external diameter and the area of the LCU tips are reported in Table 2. The designs of the LCU tips are shown in Figure 3. The external diameter of the LCU tips ranged from 7.9 to $13.5 \mathrm{~mm}$. The internal diameter of the LCU tips ranged from 5.3 to $10.4 \mathrm{~mm}$, thus the area of the LCU tips ranged from 22.06 to $84.95 \mathrm{~mm}^{2}$.

All LCUs could reach the anterior sensor equally well, however their ability to access posterior tooth varied considerably. Figure 4 illustrates the excellent ability of Valo Cordless to reach the posterior sensor whereas the light tip of the Demetron 501 could only reach the posterior sensor at an angle to the occlusal surface.

The irradiance and emission spectra emitted by LCUs are reported in Table 2 and Figures 5 to 8. Two-way ANOVA showed that the LCUs $(p<0.001)$, the tooth position $(p<0.001)$, and the interaction between LCUs and tooth position ( $p<0.001)$, significantly influenced the irradiance and the emission spectra from the LCUs. Tukey test showed that only Valo, Bluephase G2, Radii Plus, KON-LUX and Altlux II delivered a similar irradiance to both the anterior and posterior tooth locations. All other LCUs delivered a lower irradiance at posterior region compared at anterior location. KON-LUX and the Altlux II delivered an irradiance that was significantly lower than the $500 \mathrm{~mW} / \mathrm{cm}^{2}$ minimum

Table 2. Diameter of the light tips and radiant power

\begin{tabular}{|c|c|c|c|c|c|}
\hline Light curing units & $\begin{array}{c}\text { Tip external } \\
\text { diameter }(\mathrm{mm})\end{array}$ & $\begin{array}{c}\text { Tip internal } \\
\text { diameter }(\mathrm{mm})\end{array}$ & Tip Area $\left(\mathrm{cm}^{2}\right)$ & Power (mW) & $\begin{array}{c}\text { Calculated irradiance } \\
\left(\mathrm{mW} / \mathrm{cm}^{2}\right)\end{array}$ \\
\hline Bluephase G2 & 9.8 & 8.4 & 0.55 & $1226.0(6.1)$ & 2301.0 \\
\hline Optilight Max & 8.0 & 7.4 & 0.43 & $1199.0(25.2)$ & 2788.4 \\
\hline Led Lux II & 7.8 & 7.1 & 0.40 & $894.3(6.0)$ & 2235.7 \\
\hline Emitter D & 8.2 & 7.2 & 0.41 & $858.7(2.3)$ & 2094.4 \\
\hline VALO Cordless & 13.1 & 9.6 & 0.72 & $842.0(6.6)$ & 1169.4 \\
\hline LED 3M ESPE & 7.9 & 6.9 & 0.37 & $834.0(12.2)$ & 2254.1 \\
\hline Radii cal & 12.4 & 6.0 & 0.28 & $684.0(3.6)$ & 2442.9 \\
\hline EC450 & 8.2 & 7.2 & 0.41 & $659.3(22.7)$ & 1608.0 \\
\hline Curing Light XL 3000 & 7.8 & 7.3 & 0.42 & $654.0(10.4)$ & 1557.1 \\
\hline Optilight Color & 7.9 & 6.6 & 0.34 & $618.3(10.1)$ & 1818.5 \\
\hline Optilux 501 & 12.2 & 10.4 & 0.85 & $612.3(32.3)$ & 720.4 \\
\hline Emitter C & 7.9 & 7.3 & 0.42 & $594.3(11.0)$ & 1415.0 \\
\hline Radii plus & 12.4 & 5.8 & 0.26 & $543.7(18.3)$ & 2091.2 \\
\hline DB 685 & 7.9 & 6.8 & 0.36 & $497.3(9.6)$ & 1381.4 \\
\hline Poly Wireless & 8.2 & 7.3 & 0.42 & $486.7(6.1)$ & 1158.8 \\
\hline DX Turbo LED 1200 & 8.3 & 7.1 & 0.40 & 469.7 (13.0) & 1174.3 \\
\hline TL-01 & 9.2 & 5.7 & 0.26 & 367.3 (13.6) & 1412.7 \\
\hline Demetron LC & 7.9 & 7.1 & 0.40 & $348.3(2.1)$ & 870.8 \\
\hline EC500 & 8.2 & 7.1 & 0.40 & 329.3 (15.5) & 823.3 \\
\hline KON-LUX & 13.5 & 5.3 & 0.22 & $325.3(4.2)$ & 1478.6 \\
\hline BioLux Standard & 8.0 & 7.9 & 0.49 & $176.7(7.8)$ & 360.6 \\
\hline Alt Lux II & 8.2 & 7.6 & 0.45 & $175.7(6.4)$ & 390.5 \\
\hline
\end{tabular}




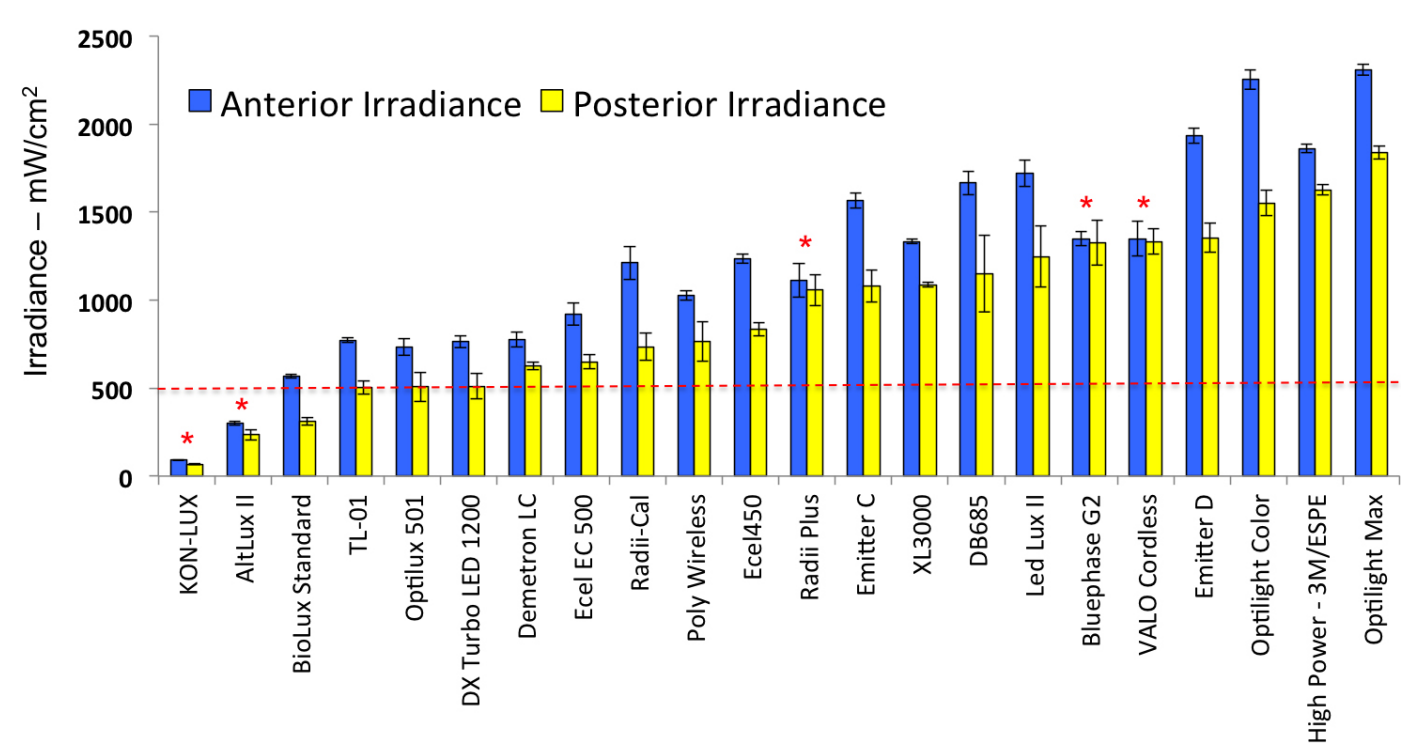

Figure 5. Irradiance values that were emitted for LCUs when used in anterior and posterior tooth sensor. "Lights that delivered similar irradiance in both locations.

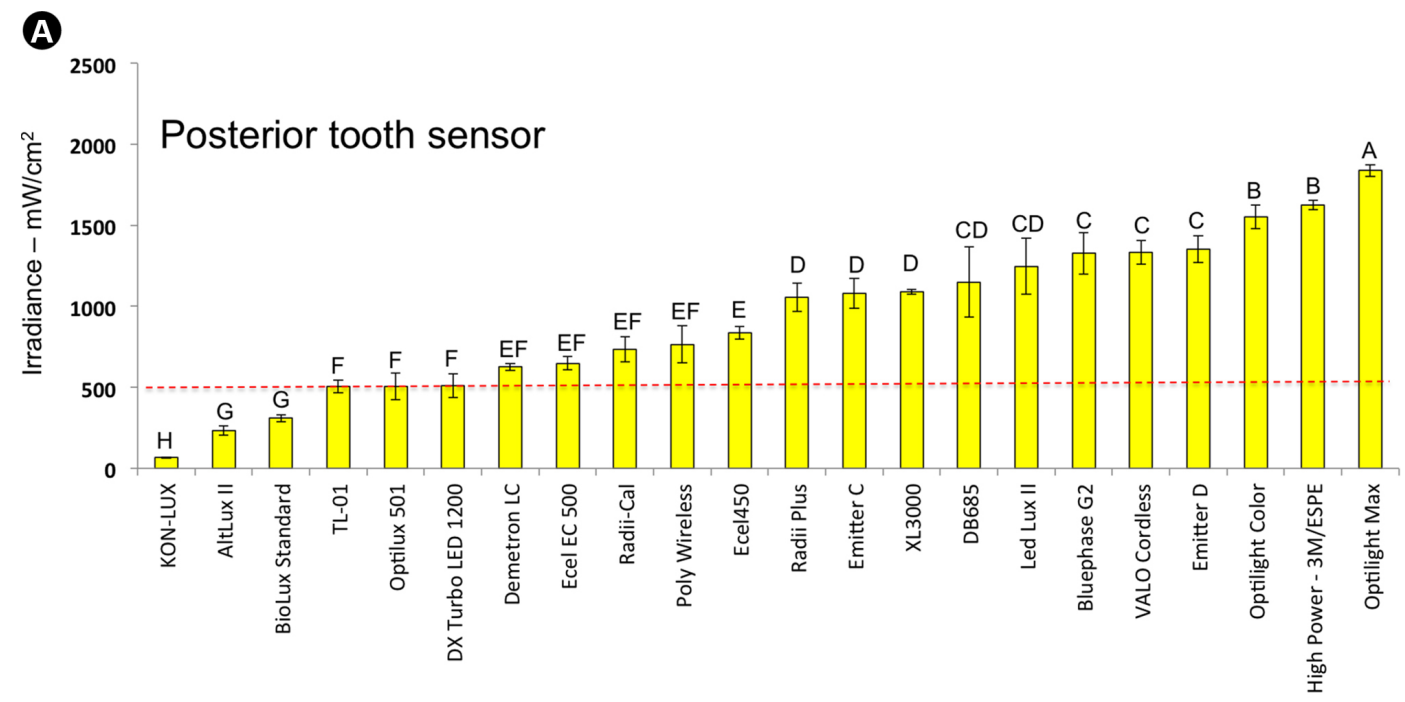

B

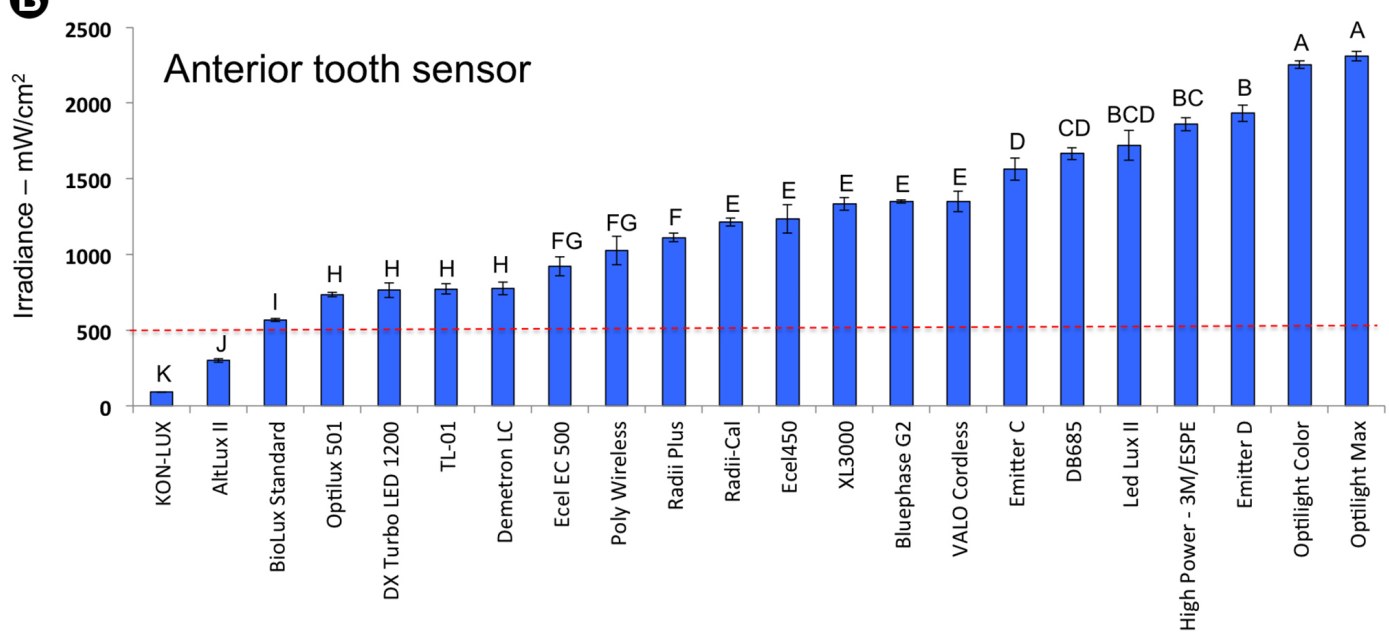

Figure 6. Irradiance values delivered by LCUs when used in: A: posterior sensor location; B: anterior sensor location. Different letters mean significant difference between LCUs at each tooth sensor. 
irradiance to both the anterior and posterior sensors.

Tukey test showed that Optilight Max, Higher-Power 3M-ESPE delivered the highest irradiance and KON-LUX, Altlux II and Biolux Standard delivered the lowest irradiance to the posterior sensor. Six LCUs delivered an irradiance that was less than the one recommended when used in posterior region: KON-LUX, Altlux II, Biolux Standard, TL-01, Optilux 501, DX Turbo LED 1200. Tukey test showed that the Optilight Max, Optilight Color had the highest irradiance; KON-LUX and Altlux II had the lowest irradiance recorded at the anterior sensor. The KON-LUX and Altlux II LCUs also delivered an inadequate irradiance to the anterior sensor.

Figure 7A illustrates the different emission spectra by the $\mathrm{OHT}$, monowave and multi-peak LED units. Figure 7B shows the difference in the spectrum emitted by two multipeak LED LCUs tested in this study. The lower wavelengths reached different values for these two LCUs. The multi-peak LCUs delivered a similar irradiance (Fig. 8A) and spectra to both sensors (Fig. 8C). The irradiance (Fig. 8B) and spectral radiant power values (Fig. 8D) of the monowave LED LCUs were lower when measured at the posterior location compared to the anterior location.

\section{Discussion}

The first hypothesis was rejected since the QTH and the LED LCUs delivered different irradiance and spectral radiant power values to the sensors in the anterior and posterior teeth. The shape of the different curing tips also affected the amount of light delivered at the two sensor locations (anterior and posterior).

The operator visibility and access was the worst in the posterior region, where the $35 \mathrm{~mm}$ interincisal opening negatively affected the irradiance results. This is not surprising, because as the distance from the light tip to the target surface increases, not all the light emitted from the light tip reaches the target and the RBC will receive less energy. This loss means that there is a risk that the RBCs will not be adequately light cured (1) Most LCUs showed
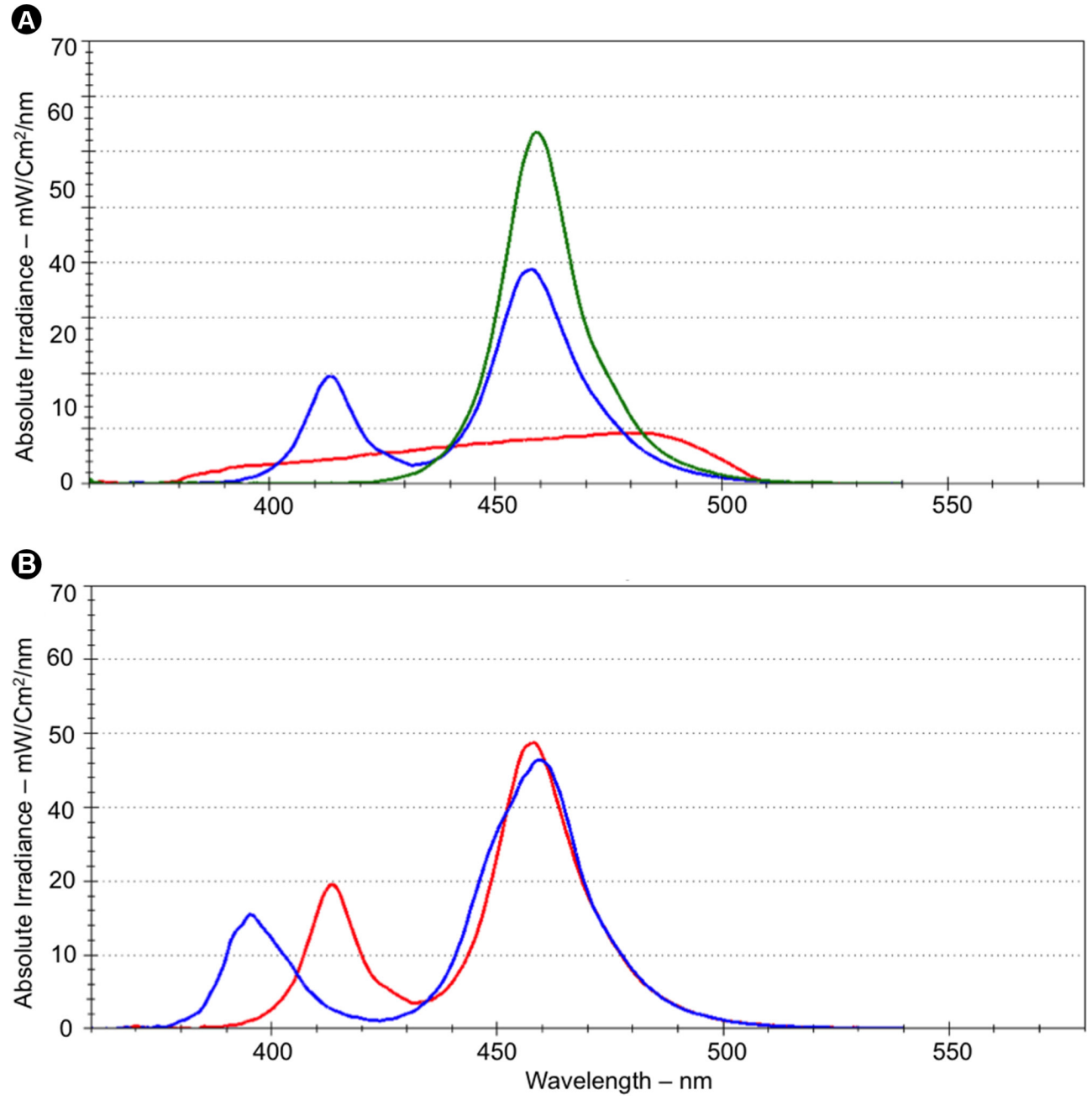

Figure 7. A: Emission spectrum showing the different wavelength peaks of a QHT LCU (red line); a monowave LED LCU (green line) and a multipeak LED LCU (blue line); B: Emission spectrum and wavelength peaks of two multi-peak LED LCUs. 
a significant decrease in the irradiance when the light was delivered to the posterior sensor compared with the anterior sensor. Although the operator was skilled and used eye protection when using the $L C U$, it was difficult to position the light tip directly over the posterior sensor. Despite this difficulty, the operator kept the LCU over the tooth and the irradiance delivered remained steady in all cases.

A previous study has also reported that access to the Class I sensor at the posterior location is more difficult than to the Class 3 sensor at the anterior location (18). The optic design and the ability of the operator to effectively position the LCU in the oral cavity may be possible factors that affect this difference (19). In this study, Valo, Bluephase G2, Radii Plus, KON-LUX and Altlux II delivered similar irradiance values to the anterior and posterior sensor tooth. On the other hand, KON-LUX e Altlux II delivered less than $500 \mathrm{~mW} / \mathrm{cm}^{2}$ to both sensors, which was considered to be inadequate.

The irradiance value of $500 \mathrm{~mW} / \mathrm{cm}^{2}$ was the minimum threshold set in this study for adequate photocuring and achieving adequate mechanical properties for the RBCs. Given that dentists wish to reduce the time spent light curing, this value was considered to be the minimum

A


irradiance necessary to adequately polymerize a $2 \mathrm{~mm}$ increment of composite $(20,21)$. Six LCUs delivered inadequate irradiance in posterior region: KON-LUX, Altlux II, Biolux Standard, TL-01, Optilux 501, DX Turbo LED 1200. In the anterior region, only two LCUs delivered an irradiance less than $500 \mathrm{~mW} / \mathrm{cm}^{2}$. Incomplete polymerization of dental RBCs can lead to a multitude of clinical problems. For example: increased discoloration, lower bond strengths, more gingival marginal defects, decreased hardness, decreased flexural strength, pulp irritation, greater postoperative sensitivity, lower fracture strengths, decreased dynamic elastic modulus, lower resistance to abrasive wear and eventual failure of the restoration $(22,23)$.

Clinicians often light cure the entire adhesive systems in MOD preparations just once and then also light cure the entire restoration using only one light exposure. This and other studies show that the orientation of the LCU tip over the tooth in some areas, such as the proximal boxes, will influence the received irradiance (22). The angled design of the light tip means that it creates an angle when placed over the molar that may well result in a lower irradiance being delivered to the distal proximal box of a MOD restoration. This may result in the resin being inadequately polymerized

B
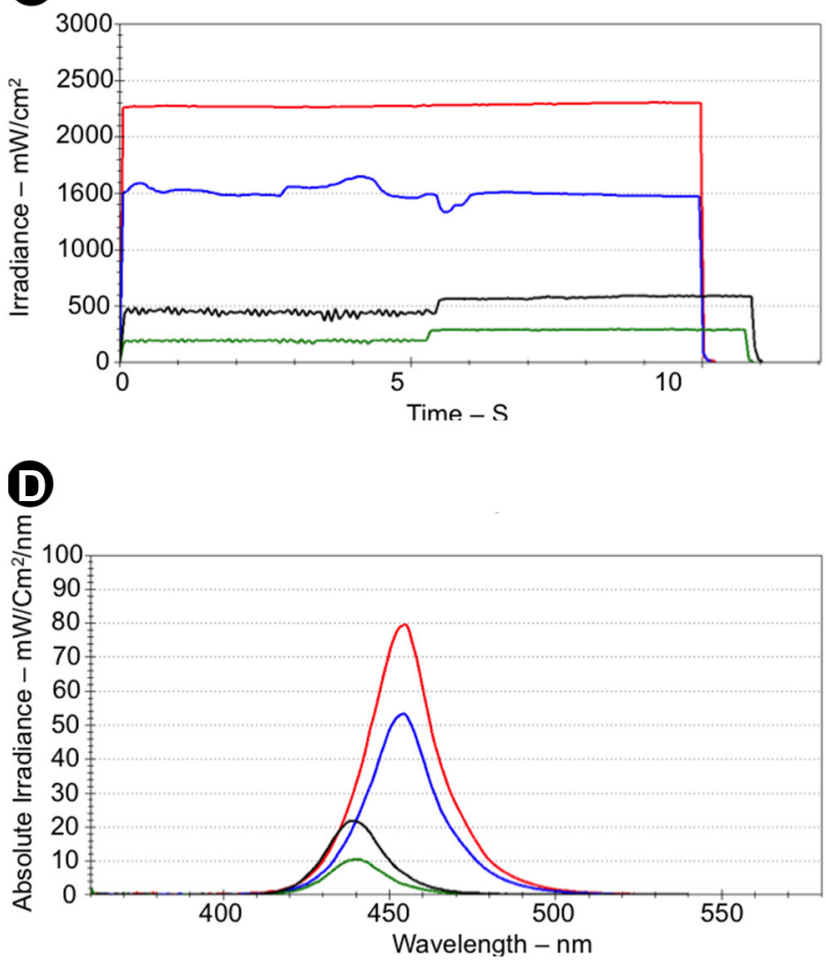

Figure 8. Effect of sensor location on the irradiance and emission spectrum of representative LCUs; A: Example of a LCU that delivered similar high irradiance (black and green lines) to both the anterior and posterior sensor and a LCU that delivered low irradiance (red and blue lines to the same sensors); B: Example of LCUs that delivered higher irradiance at anterior sensor (red and black lines) and lower irradiance at posterior sensor (blue and green lines); C: Example of a multi-peak emission spectrum delivered (black and green lines) and low irradiance (red and blue lines) that delivered a similar spectrum and irradiance to both the anterior and posterior sensors; D: Example of LCUs that emitted higher spectrum and wavelength peaks to the anterior sensor (red and blue lines) but a lower irradiance to posterior sensor (black and green lines). 
at the bottom of the proximal box. Another aspect that affects the performance of the LCU is the area of the tip. Even if the LCU has a homogeneous light output and has a wide $10 \mathrm{~mm}$ outside diameter tip, if the tip diameter does not cover the restoration, then the polymerization process can be compromised. Since the molar teeth have in average $10 \mathrm{~mm}$ in medial-distal dimension; only 3 LCUs (Demetron 501, Valo Cordless and Bluephase G2) are able to cover the area of the entire MOD restoration with the tip of the LCU. The tested scenario in this study would be even worse if the irradiance had been measured at the gingival floor of a proximal box, where the effects of an increased distance and the tip inclination will further reduce the irradiance. Thus despite some advertising claims that the dentist need light cure a bulk-fill RBC only once, the clinician may still have to light cure a bulk-fill RBC restoration more than once so that all of the restoration receives sufficient light (20)

Manufacturers and researchers should provide detailed information about the radiant power ( $\mathrm{mW})$, irradiance, the effect of distance on the irradiance, and the emission spectrum across the light tip when describing the LCU (2), so that the dentist can make an informed decision about the choice of LCU, the exposure time and photoactivation technique (20). Clinicians should periodically check their LCUs by measuring the irradiance and they should consider the effect of different shades and opacity of the RBC on the exposure time. If the LCU delivers an irradiance close to 500 $\mathrm{mW} / \mathrm{cm}^{2}$, longer exposure times (40 to $60 \mathrm{~s}$ ) and multiple exposures to the occlusal, lingual and buccal surfaces are recommended. Alternately, the clinicians should seriously consider replacing the LCU.

Further studies are required to characterize the active area of the LCU optic tip from where light is emitted, and to correlate the irradiance across the light tip with the hardness values of various RBCs and determine the effects of any non-uniformity in the irradiance on the RBC. At present, it is recommended that clinicians use an LCU with large tip area that emits a homogeneous irradiance across the tip greater than $500 \mathrm{mw} / \mathrm{cm}^{2}$. The effects of distance up to $8 \mathrm{~mm}$ away on the irradiance should be small and the LCU should be able to deliver the same irradiance to both anterior and posterior sensors.

\section{Resumo}

Este estudo mediu a potência $(\mathrm{mW})$, irradiância $\left(\mathrm{mW} / \mathrm{cm}^{2}\right)$ e espectro da luz (mW/ $\mathrm{cm}^{2} / \mathrm{nm}$ ) emitida por 22 fontes de luz (Alt Lux II, BioLux Standard, Bluephase G2, Curing Light XL 3000, Demetron LC, DX Turbo LED 1200, EC450, EC500, Emitter C, Emitter D, KON-LUX, LED 3M ESPE, Led Lux II, Optilight Color, Optilight Max, Optilux 501, Poly Wireless, Radii cal, Radii plus, TL-01, VALO Cordless) disponiveis comercialmente. A potência emitida pelas fontes de luz foi medida usando um medidor laboratorial de potencia com grade a laser. A área $\left(\mathrm{cm}^{2}\right)$ da ponta ativa efetiva das fontes de luz foi medida com paquimetro digital e utilizada para calcular a irradiância emitida. 0 simulador de paciente-MARC (MARC - PS) com espectrómetro (USB4000, Ocean Optics) foi usado para medir a irradiância e o espectro de luz emitida por cada fonte de luz na região anterior e posterior. Esta medição foi repetida por três vezes em dois sensores localizados na região anterior e posterior da arcada dentária. Os dados de irradiância foram analisados utilizando análise de variância em dois fatores, e os dados de potência foram analisados com análise de variância em fator único seguido pelo teste de Tukey $(\alpha=0,05)$. As fontes de luz Valo, Bluephase G2, Radii Plus emitiram irradiância semelhante tanto na região anterior como posterior com valores superiores ao mínimo de $500 \mathrm{~mW} / \mathrm{cm}^{2}$. Seis fontes de luz emitiram irradiância menor que o recomendado ( $500 \mathrm{~mW}$ / $\mathrm{cm}^{2}$ ) quando usadas na região posterior: Kon-lux, Altlux II, Biolux Standard TL-01, Optilux 501, DX Turbo LED 1200 e duas quando usadas na região anterior: Kon-lux e Altlux II LCUs. As fontes Bluephase G2, Optilight Max emitiram os maiores valores de potência e as fontes de luz Altlux II e Biolux Standard emitiram os menores valores de potência. 0 espectro de luz das fontes LED de espectro único variou de forma evidente entre as fontes. As fontes LED multi pico de espectro emitiram espectros de luz similar para ambos os sensores. A fotoativação na região posterior tende a reduzir substancialmente a irradiância da maioria das fontes de luzes testadas.

\section{References}

1. Rueggeberg FA. State-of-the-art: dental photocuring - a review. Dent Mater 2011;27:39-52.

2. Price RB, Ferracane JL, Shortall AC. Light-curing units: a review of what we need to know. J Dent Res 2015;94:1179-1186.

3. Scimago Journal \& Country Rank, Dentistry - All Subjects categories - All regions. http://www.scimagojr.com/countryrank. php?area $=3500$ \&tyear $=2015$

4. Nomoto R. Effect of light wavelength on polymerization of light-cured resins. Dent Mater J 1997;16:60-73.

5. Leprince JG, Palin WM, Hadis MA, Devaux J, Leloup G. Progress in dimethacrylate-based dental composite technology and curing efficiency. Dent Mater 2013;29:139-156.

6. Lima AC, Rached-Junior FJ, Faria NS, Messias DC, Chaves CA, Freitas $J V$, et al.. Influence of sealer and light-curing units on push-out bond strength of composite resin to weakened roots. Braz Dent J 2016;27:430-435.

7. Segreto DR, Naufel FS, Brandt WC, Guiraldo RD, Correr-Sobrinho L, Sinhoreti MA. Influence of photoinitiator and light-curing source on bond strength of experimental resin cements to dentin. Braz Dent J 2016;27:83-89.

8. Pereira CN, De Magalhães CS, Daleprane B, Peixoto RT, Ferreira RC, Cury LA, et al.. LED and halogen light transmission through a CAD/CAM lithium disilicate glass-ceramic. Braz Dent J 2015;26:648-653.

9. Jandt KD, Mills RW. A brief history of LED photopolymerization. Dent Mater 2013;29:605-617

10. Harlow JE, Sullivan B, Shortall AC, Labrie D, Price RB. Characterizing the output settings of dental curing lights. J Dent 2016;44:20-26.

11. Jandt KD, Mills RW. A brief history of LED photopolymerization. Dent Mater 2013;29:605-617

12. Porto IC, Soares LE, Martin AA, Cavalli V, Liporoni PC. Influence of the photoinitiator system and light photoactivation units on the degree of conversion of dental composites. Braz Oral Res 2010;24:475-481.

13. Santini A, Gallegos IT, Felix CM. Photoinitiators in dentistry: a review. Prim Dent J 2013;2:30-33.

14. Hadis M, Leprince JG, Shortall AC, Devaux J, Leloup G, Palin WM. High irradiance curing and anomalies of exposure reciprocity law in resinbased materials. J Dent 2011;39:549-557.

15. Guiraldo RD, Consani S, Consani RLX, Fugolin APP. Evaluation of the power density and the light spectrum of light from light-curing units used in dental clinics. Cienc Odontol Bras 2008;11:86-90.

16. Soares CJ, Rodrigues MP, Vilela ABF, Rizo ERC, Ferreira LB, Giannini M, et al.. Evaluation of eye protection filters used with broad-spectrum and conventional LED curing lights. Braz Dent J 2017;28:9-15.

17. Federlin $M_{1}$ Price R. Improving light-curing instruction in dental school. J Dent Educ 2013;77:764-772.

18. Mutluay MM, Rueggeberg FA, Price RB. Effect of using proper 
light-curing techniques on energy delivered to a Class 1 restoration. Quintessence Int 2014;45:549-556.

19. Bhatt $S$, Ayer $C D$, Price RB, Perry R. Effect of curing light and restoration location on energy delivered. Compend Contin Educ Dent 2015;36:208-214.

20. Shimokawa CA, Turbino ML, Harlow JE, Price HL, Price RB. Light output from six battery operated dental curing lights. Mater Sci Eng $C$ Mater Biol Appl 2016;69:1036-1042.

21. Beolchi RS, Moura-Netto C, Palo RM, Rocha Gomes Torres C, Pelissier B. Changes in irradiance and energy density in relation to different curing distances. Braz Oral Res 2015;29:1-7
22. Michaud PL, Price RB, Labrie D, Rueggeberg FA, Sullivan B. Localised irradiance distribution found in dental light curing units. J Dent 2014;42:129-139.

23. Vandewalle KS, Roberts HW, Rueggeberg FA. Power distribution across the face of different light guides and its effect on composite surface microhardness. J Esthet Restor Dent 2008;20:108-117.

Received December 16, 2016 Accepted March 14, 2017 